\title{
BIOMECHANICAL ANALYSES OF RISING FROM A CHAIR
}

\author{
Albert B. Schultz, ${ }^{*} \dagger$ Neil B. AleXander $\ddagger$ and James A. Ashton-Miller* \\ *Department of Mechanical Engineering and Applied Mechanics, †Institute of Gerontology and \\ $\ddagger$ Division of Geriatric Medicine and GRECC-VA Medical Center, University of Michigan, Ann Arbor, \\ MI 48109-2125, U.S.A
}

\begin{abstract}
Quantification of the biomechanical factors that underlie the inability to rise from a chair can help explain why this disability occurs and can aid in the design of chairs and of therapeutic intervention programs. Experimental data collected earlier from 17 young adult and two groups of elderly subjects, 23 healthy and 11 impaired, rising from a standard chair under controlled conditions were analyzed using a planar biomechanical model. The joint torque strength requirements and the location of the floor reaction force at liftoff from the seat in the different groups and under several conditions were calculated. Analyses were also made of how body configurations and the use of hand force affect these joint torques and reaction locations.

In all three groups, the required torques at liftoff were modest compared to literature data on voluntary strengths. Among the three groups rising with the use of hands, at the time of liftoff from the seat, the impaired old subjects, on an average, placed the reaction force the most anterior, the healthy old subjects placed it intermediately and the young subjects placed it the least anterior, within the foot support area. Moreover, the results suggest that, at liftoff, all subjects placed more importance on locating the floor reaction force to achieve acceptable postural stability than on diminishing the magnitudes of the needed joint muscle strengths.
\end{abstract}

\section{INTRODUCTION}

More than two million persons older than 64 years in the United States alone have difficulty in rising from a chair (Dawson et al., 1987). Inability to rise independently often contributes to institutionalization. Rising from a chair requires that adequate torques be developed about each of the body's joints and that, at least in slowly performed rises, the location of the vertical component of the floor support force at liftoff from the seat be brought to within the area of the foot support. Comparisons of the maximum joint torques that an individual can develop with the torques needed to rise, and analyses of his placement of the support force location can provide insights into the biomechanical determinants of the ability to rise from a chair. This understanding can, in turn, be used to determine the sources of inability to rise, to design more suitable chairs, and to devise more effective therapeutic intervention programs.

Many studies concerned with chair rise biomechanics have been reported. These include observations, during a rise, of body kinematics (Jones et al., 1962; Kelley et al., 1976; Ellis et al., 1979, 1985; Bajd et al., 1982; Nemeth et al., 1984; Burdett et al., 1985; Wheeler et al., 1985; Nuzik et al., 1986; Fleckenstein et al., 1988; Stevens et al., 1989; Rodosky et al., 1989; Jeng et al., 1990; Kralj et al., 1990; Schenkman et al., 1990; Riley et al., 1991), foot/floor reaction forces (Ellis et al., 1979, 1985; Bajd et al., 1982; Nemeth et al., 1984; Burdett et

Received in final form 3 June 1992.

Address correspondence to: Albert B. Schultz, Department of Mechanical Engineering, University of Michigan, Ann Arbor, MI 48109-2125, U.S.A. al., 1985; Stevens et al., 1989; Rodosky et al., 1989; Seedhom et al., 1976; Yoshida et al., 1985), myoelectric activities (Kelley et al., 1976; Munton et al., 1984; Nemeth et al., 1984; Wheeler et al., 1985; Ellis et al., 1985; Stevens et al., 1989), and biomechanical model analyses (Kelley et al., 1976; Seedhom et al., 1976; Ellis et al., 1979, 1985; Bajd et al., 1982; Nemeth et al., 1984; Burdett et al., 1985; Fleckenstein et al., 1988; Rodosky et al., 1989; Ikeda et al., 1991; Pai and Rogers, 1990, 1991). Nevertheless, no comprehensive analyses of what factors affect the joint torques and floor reaction locations or of why chair rise strategies might differ between young and elderly adults seem available.

In the present study, experimental data collected earlier from young adult and two groups of elderly subjects, one healthy and one impaired, rising from a standard chair under controlled conditions were analyzed using a planar biomechanical model. The analyses addressed the following questions:

(1) What individual body segment movements are most effective in helping to bring the floor reaction location to its required location within the area of the foot support?

(2) Were there notable subject age and impairment group differences in the location of the floor reaction at liftoff?

(3) What joint torques were used in rising?

(4) Were there notable subject age and impairment group differences in the torques used?

(5) How did the torques used compare with literature data on maximum torque strengths?

(6) What might explain the different choices for mean body configurations and hand force use at liftoff among the age and impairment groups?

To keep the analyses relatively simple, only slowly performed, sagittally symmetric rises from carefully 
Table 1. Mean Phase 1 body segment rotation data* $\left({ }^{\circ}\right)$ used in analyses

\begin{tabular}{lcccccccc}
\hline & \multicolumn{3}{c}{ With hand use } & & \multicolumn{3}{c}{ Without hand use } \\
\cline { 2 - 4 } \cline { 7 - 9 } Group & Leg & Thigh & $\begin{array}{c}\text { Upper } \\
\text { body }\end{array}$ & & Leg & Thigh & $\begin{array}{c}\text { Upper } \\
\text { body }\end{array}$ \\
\hline Young & 4.6 & 10.5 & 32.8 & & 5.9 & 11.2 & 37.2 \\
Old able & 6.3 & 15.7 & 33.2 & & 8.2 & 15.7 & 42.9 \\
Old unable & 8.1 & 11.0 & 42.4 & & & & \\
\hline
\end{tabular}

Positive entries correspond to rotations in leg flexion, thigh extension and upper-body flexion.

* Data from Alexander et al. (1991).

controlled initial conditions were studied. Conditions primarily at the time of liftoff from the seat support were analyzed.

\section{METHODS}

\section{Configuration and hand force experimental data analyzed}

A companion paper (Alexander et al., 1991) reports biomechanical measurements of chair rise performances made in three subject groups. Two of the groups consisted of 17 healthy young adults (young group) and 23 healthy elderly adults (old able group), all of whom were able to rise both with and without the use of hands from an instrumented laboratory chair under controlled initial conditions. The third group consisted of another 11 elderly females who were unable to rise under the standard conditions investigated without the use of hands, but could rise when hand use was allowed (old unable group). Body segment motions during sagittally symmetric chair rises were divided into two phases. In Phase 1, body segment movements were essentially anterior. In Phase 2 they were essentially vertical. Liftoff from the seat occurred approximately at the end of Phase 1 . The data of Alexander et al. (Table 1) were used to define the Phase 1 end configurations that were analyzed with the model. Their data on mean measured peak hand forces (Table 2) were used in studies concerning the effects of hand force use. It was assumed for the present studies that the peak horizontal and vertical forces occurred at the end of Phase 1, since Alexander et al. found this to be approximately correct.

\section{Biomechanical model}

The biomechanical model used for all analyses consisted of 10 linked rigid bodies; one each to represent the feet, lower legs, thighs, pelvis, lower trunk, upper trunk, head and neck, upper arms, forearms, and hands (Fig. 1). All the links were assumed to move only in the sagittal plane. Each link was assigned a length, a mass center location and a mass scaled to each subject's height and weight from standard an-
Table 2. Mean peak hand force data* used in analyses

\begin{tabular}{lcccc}
\hline Group & $\begin{array}{c}\text { Total } \dagger \\
\text { horizontal } \\
(\mathrm{N})\end{array}$ & $\begin{array}{c}\text { Total } \dagger \\
\text { vertical } \\
(\mathbf{N})\end{array}$ & $\begin{array}{c}\text { Resultant } \\
\text { force } \\
(\mathbf{N})\end{array}$ & $\begin{array}{c}\text { Force } \\
\text { angle } \ddagger \\
\left({ }^{\circ}\right)\end{array}$ \\
\hline Young & 106 & 84 & 154 & 51.5 \\
Old able & 98 & 94 & 144 & 49.1 \\
Old unable & 129 & 82 & 159 & 56.9 \\
\hline
\end{tabular}

*Data from Alexander et al. (1991).

$\uparrow$ Sums over two hands. Forces are those exerted by the handles on the hands.

$\ddagger$ Measured counterclockwise from the anterior horizontal direction.

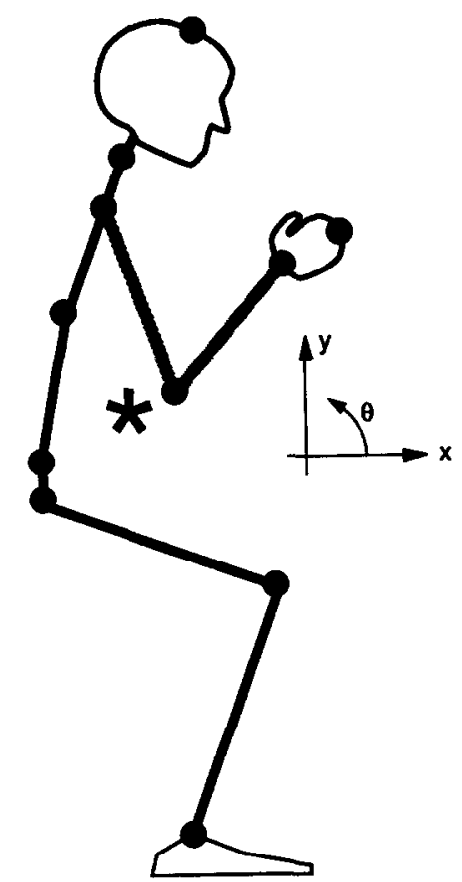

Fig. 1. Schematic diagram of the 10-rigid-link biomechanical model used to calculate the net joint torques and the total body mass center and vertical floor reaction locations. If hand forces are not used to assist the rise, the vertical floor reaction force will lie directly inferior to the location of the total body mass center, which is shown by the asterisk. 
Table 3. Anthropometric data (\%) incorporated in the biomechanical model

Link masses, lengths and center of mass (CM) locations when standing with arms overhead

\begin{tabular}{|c|c|c|c|c|}
\hline & $\begin{array}{c}\text { Mass of } \\
\text { link }\end{array}$ & $\begin{array}{l}\text { Height of } \\
\text { CM }\end{array}$ & $\begin{array}{l}\text { Length of } \\
\text { link }\end{array}$ & $\begin{array}{l}\text { Distance inferior } \\
\text { joint to } \mathrm{CM}\end{array}$ \\
\hline Feet & 3.4 & 1.8 & 3.9 & 1.8 \\
\hline Lower lcgs & 9.6 & 18.2 & 24.6 & 14.3 \\
\hline Upper legs & 21.5 & 42.5 & 23.7 & 14.0 \\
\hline Pelvis & 9.3 & 54.1 & 4.2 & 2.0 \\
\hline Lower trunk & 18.4 & 63.1 & 14.0 & 6.8 \\
\hline Upper trunk & 17.4 & 76.9 & 15.9 & 6.6 \\
\hline Head/neck & 7.9 & 92.5 & 13.8 & 6.3 \\
\hline Upper arms & 6.6 & 90.6 & 18.9 & 9.4 \\
\hline Lower arms & 4.2 & 106.9 & 16.0 & 6.8 \\
\hline Hands & 1.7 & 119.2 & 6.2 & 3.1 \\
\hline Total & 100.0 & & & \\
\hline \multicolumn{5}{|c|}{ Heights of joint centers when standing with arms overhead } \\
\hline Ankles & & 3.9 & & \\
\hline Knees & & 28.4 & & \\
\hline Hips & & 52.1 & & \\
\hline $\mathrm{L} 5 / \mathrm{S} 1$ & & 56.3 & & \\
\hline $\mathrm{T} 10$ & & 70.3 & & \\
\hline $\mathrm{C} 4$ & & 86.2 & & \\
\hline Top of head & & 100.0 & & \\
\hline Shoulders & & 81.2 & & \\
\hline Elbows & & 100.1 & & \\
\hline Wrists & & 116.1 & & \\
\hline Tip of hands & & 122.3 & & \\
\hline
\end{tabular}

Masses are given as percentage of the total body mass and distances as percentage of the total standing height. Data adapted from Anthropometric Source Book (1978).

thropometric data (Anthropometric Source Book, 1978) (Table 3).

Sets of the 10 angles that these !rks subtended at the horizontal were prescribed. Using these angles and the anthropometric data, the locations of the ankle, knee, hip, L5/S1 intervertebral, T9/T10 intervertebral, shoulder, elbow, wrist, and $\mathrm{C} 3 / \mathrm{C} 4$ intervertebral joints were calculated. The locations of the mass centers of each of the body segments were also calculated, and from these, the location of the total body mass center.

The horizontal and the vertical net reaction forces and the net reaction sagittal plane moment at each joint were then computed from the equations of equilibrium, using the segment weight and externalforce data while assuming inertial loads to be negligible. Proceeding inferiorly, link by link, from the head and hands, ultimately the net reaction at the foot/floor interface was computed, yielding the anteroposterior location of the floor reaction relative to the ankle joints. When no external forces were exerted on the hands, this reaction location lay directly below the total body mass center. Only the group means of the floor reaction location and the net reaction moments at the ankles, knees, hips and shoulders will be reported here. Student's $t$-tests were made to determine the significance of age group and hand use differences in these means.

\section{Situations examined}

Four sets of biomechanical model analyses of the required joint torques and floor reaction locations were made. In all but Set 1 , the reaction locations and the net joint torques at the end of Phase 1 were calculated.

The Set 1 analyses considered hypothetical body segment movements to explore which segment movcments contribute most to the achievement of the biomechanical requirements for rising. An initial-state calculation determined what the reaction location and the joint torques need to be in the hypothetical absence of seat and hand support forces. In this initial state, the thighs were horizontal and all the other body segments were vertical, with the arms and hands hanging down (Fig. 2). The movements examined were stretching the arms and hands anteriorly, flexing the head and upper neck by $45^{\circ}$ and $20^{\circ}$ rotations, in turn, of leg flexion, of thigh extension and of flexion of the trunk, arms and head.

The Set 2 and Set 3 analyses considered the mean observed configurations at liftoff from the seat in the two subject groups rising without and the three groups rising with the use of hands, respectively. The Set 4 analyses considered the mean observed configuration at liftoff from the seat in the old able group rising with the use of hands, but incorporated hypo- 
thetical hand forces to explore the effects of hand force use on floor reaction locations and the needed torques.

Set 3 and Set 4 calculations were made in two ways. First, the shoulders, elbows, wrists and hands were

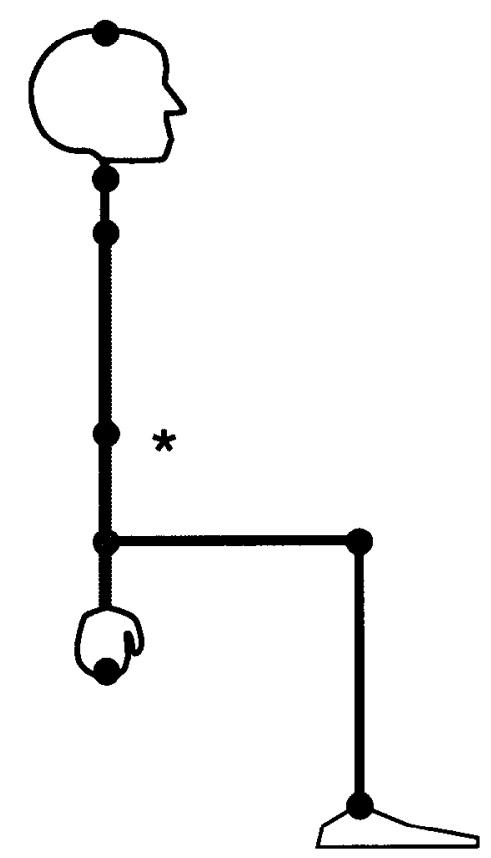

Fig. 2. Schematic diagram of the initial state used in the Set 1 analyses. The location of the total body mass center is shown by the asterisk.

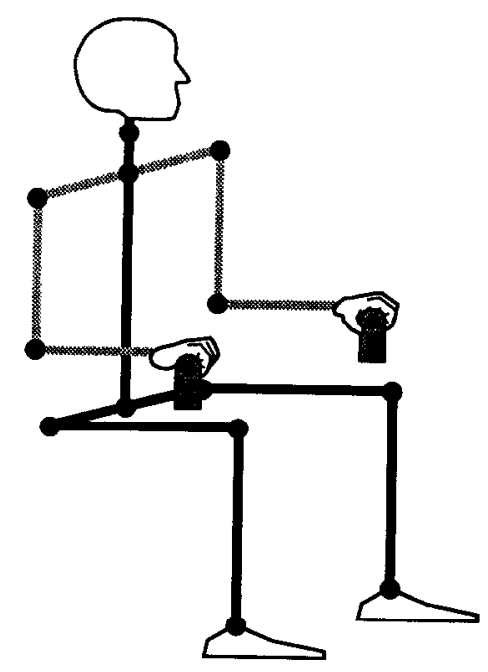

(a) assumed to lie in a sagittal plane [Fig. 3(a)]. Second, they were assumed to lie in the plane defined by a line joining the shoulders and hands and a transverse line [Fig. 3(b)]. In other words, the upper arms were abducted in the first set of calculations and maximally abducted in the second set, but hand and shoulder locations were the same in both the sets. The results from these two arm segment placements probably encompass the results that would have been obtained had the actual three-dimensional configurations of the arms been used. The actual location of the mass center of the upper extremities would lie somewhere between the mass center locations for these two arm segment placements. The mean values over these two arm configuration sets were used in further analyses.

\section{RESULTS}

Effects of hypothetical segment movements (Set 1 analyses)

People fall when a chair is pulled out from under them in a fully upright initial configuration because, in the absence of hand and seat support, the required floor reaction location for 50th percentile male anthropometry, for example, lies $33 \mathrm{~cm}$ posterior to the ankles (Table 4), or well outside the area of the foot/floor contact. Assuming that the heels are $8 \mathrm{~cm}$ posterior to the ankle joints, a slow rise can be achicved only after the reaction location is brought $25 \mathrm{~cm}$ forwards so as to have it anterior to the heels.

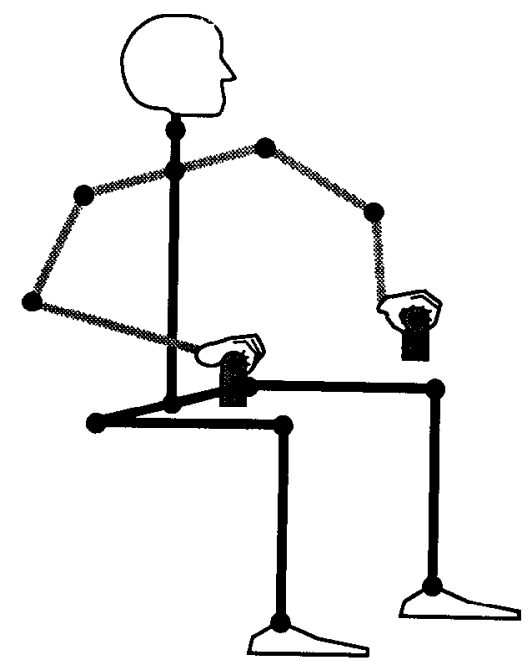

(b)

Fig. 3. Schematic diagram showing the two placements of the arms used in the Set 3 and Set 4 analyses. In each set, one analysis was made in which the shoulders, elbows and hands all lay in a sagittal plane (a). A second analysis was made in which the upper arms were maximally abducted (b). The locations of the shoulders and hands were the same in both analyses. 
Table 4. Effects of hypothetical segment movements on reaction locations and joint torques

\begin{tabular}{|c|c|c|c|c|c|}
\hline & \multirow{2}{*}{$\begin{array}{l}\text { Floor } \\
\text { Reaction } \\
\text { Location* } \\
\text { (cm) }\end{array}$} & \multicolumn{4}{|c|}{ Required joint torques $\nmid(\mathrm{N} \mathrm{m})$} \\
\hline & & Ankle & Knee & Hip & Shoulder \\
\hline Initial configuration & -33.0 & 226 & 226 & 0 & 0 \\
\hline Stretch arms forward & -28.8 & 198 & 198 & 29 & 29 \\
\hline Flex head $45^{\circ}$ & -32.4 & 222 & 222 & 4 & 0 \\
\hline Flex legs $20^{\circ}$ & -19.1 & 131 & 226 & 0 & 0 \\
\hline Extend thighs $20^{\circ}$ & -31.0 & 213 & 213 & 0 & 0 \\
\hline Flex upper body $20^{\circ}$ & -24.9 & 171 & 171 & 56 & 0 \\
\hline
\end{tabular}

*Anterior of ankle joints.

†Total for two joints. Positive entries correspond to ankle plantarflexion, knee extension, hip extension and shoulder flexion.

$\ddagger$ Thighs horizontal, arms down, all other segments vertical. Seat and hand support forces were assumed to be zero for this calculation.

Moving body segments anteriorly helps to do this, but flexing the head and neck $45^{\circ}$ moves the reaction location only by $0.6 \mathrm{~cm}$, bringing it to $32.4 \mathrm{~cm}$ posterior of the ankles. Extending the arms moves the reaction location by $4.2 \mathrm{~cm}$, bringing it to $28.8 \mathrm{~cm}$ posterior of the ankles. The effects of the $20^{\circ}$ segment rotations studied show that also thigh extension by itself has little effect. Upper-body flexion moves the reaction forward by $8.1 \mathrm{~cm}$, bringing it to $24.9 \mathrm{~cm}$ posterior of the ankles. The most effective $20^{\circ}$ body segment rotation is a flexion of the legs. This amount of leg flexion moves the reaction forward by $13.9 \mathrm{~cm}$ of the required $25 \mathrm{~cm}$. The effects of these hypothetical segment movements on the required joint torques were variable (Table 4).

Thus, in answer to question (1), flexing the lower legs to bring the feet under the upper body segments is perhaps the most effective maneuver to facilitate rising from a chair. Forward flexion of body segments superior to the hips is also effective.

\section{Reaction locations (Set 2 and Set 3 analyses)}

In answer to question (2), both the young and the old able groups who rose without the use of hands brought the floor reaction at liftoff close to the ankles (Table 5). The mean location in the young subjects was $1.5 \mathrm{~cm}$ posterior of the ankles, while in the old able subjects it was $1.9 \mathrm{~cm}$ anterior of the ankles. The old able subjects achieved this by using larger segment rotations at liftoff (Alexander et al., 1991).

All three subject groups when rising with the use of hands brought the floor reaction at liftoff anterior to the ankles (Table 5). Both the young and the old able groups brought the floor reaction further anterior when they rose using their hands compared to when they rose without hand use (Table 5). Moreover, when using hands, the old unable group placed the floor reaction the most anterior $(10.7 \mathrm{~cm})$ to the ankles, the old able group placed it intermediately $(7.1 \mathrm{~cm})$ and the young group placed it the least anterior $(4.4 \mathrm{~cm})$ to the ankles.

\section{Required torques (Set 2 and Set 3 analyses)}

With regard to question (3), the model-calculated joint torques required at liftoff from the seat when rising either without or with hand use (Table 5 provides both absolute torques and torques expressed as a percentage of the product of body weight and height) showed that ankle plantarfiexor strengths needed were at most $39 \mathrm{~N} \mathrm{~m}$. The required knee extensor and hip extensor torques were at most 119 and $96 \mathrm{Nm}$, respectively, and the required shoulder flexor torques were at most $37 \mathrm{Nm}$.

When rising without the use of hands, both groups reduced substantially the ankle and knee torques needed at liftoff compared to those needed in unsupported initial configurations, but at the expense of requiring small shoulder flexor and moderate hip extensor torques (Tables 4 and 5).

Hand use increased the mean ankle and shoulder torques from their no-hand-use values in the two groups who could also rise without the use of hands, young and old able. However, hand use decreased the required hip and knee torques from no-hand-use values by up to $35 \mathrm{Nm}$ (Table 5).

In answer to question (4), with or without hand use, the old able subjects did not choose to reduce the required joint torques appreciably compared to those of the young subjects. The old unable group rising using hands, compared to the two more able groups, opted for marked reductions in the required joint torques at the knees and shoulders, but not at the ankles and hips.

\section{Use of hand forces (Set 4 analyses)}

The three subject groups, when rising with the use of hands, developed a three-group-mean resultant hand 
Table 5. Mean reaction locations and joint torques at liftoff from seat

\begin{tabular}{|c|c|c|c|c|c|c|c|c|c|}
\hline \multirow[b]{2}{*}{ Group } & \multirow{2}{*}{$\begin{array}{l}\text { Floor } \\
\text { reaction } \\
\text { location } \\
(\mathrm{cm})^{*}\end{array}$} & \multirow[b]{2}{*}{ Ankle } & \multicolumn{2}{|c|}{$\begin{array}{l}\text { Required joint torques** } \\
\text { Absolute }(\mathrm{N} \mathrm{m})\end{array}$} & \multirow[b]{2}{*}{ Shoulder } & \multicolumn{4}{|c|}{$\begin{array}{l}\text { Required joint torques** } \\
\text { Percent of body weight } \times \text { height }\end{array}$} \\
\hline & & & Knee & Hip & & Ankle & Knee & Hip & Shoulder \\
\hline \multicolumn{10}{|c|}{ Without the use of hands } \\
\hline Young & $-1.5(3.2)$ & $-8(21)$ & $119(20)$ & $82(24)$ & $8(2)$ & -0.87 & 10.82 & 7.31 & 0.68 \\
\hline Old able & $1.9(2.9) \ddagger$ & $14(22) \dagger$ & $112(32)$ & $96(32)$ & $9(3)$ & 1.12 & 9.62 & 8.15 & 0.75 \\
\hline \multicolumn{10}{|c|}{ With the use of hands } \\
\hline Young & $4.4(5.9)^{*} \S$ & $21(33)^{*} \ddagger$ & $99(20) \S$ & $53(19) \uparrow$ & $32(25)^{*} \pi$ & 1.77 & 8.96 & 4.75 & 2.88 \\
\hline Old able & $7.1(6.9)^{*} \S$ & $36(41)^{*}+$ & $99(33)$ & $61(25) \pi$ & $37(34) * 9$ & 3.10 & 8.45 & 5.25 & 3.15 \\
\hline Old unable & $10.7(6.1)$ & $39(19)$ & $54(15)^{* * *}$ & $46(20)$ & $17(26)$ & 4.83 & 6.42 & 5.54 & 2.06 \\
\hline
\end{tabular}

Standard deviations in parentheses.

*Anterior of ankle joints.

**Total for two joints. Positive entries correspond to ankle plantarflexion, knee extension, hip extension and shoulder flexion.

*** Old unable $<$ Old able, $p<0.001$

fOld able $>$ Young, $p<0.005$.

fOld able $>$ Young, $p<0.002$.

$\S$ With hands $<$ without hands, $p<0.01$.

TWith hands $<$ without hands, $p<0.001$.

* + With hands $>$ without hands, $p<0.05$.

$*+$ With hands $>$ without hands, $p<0.01$.

* $\S$ With hands $>$ without hands, $p<0.002$.

* TWith hands $>$ without hands, $p<0.001$.

Table 6. Effects of the use of hypothetical hand forces at liftoff on reaction locations and joint torques

\begin{tabular}{|c|c|c|c|c|c|}
\hline & \multirow{2}{*}{$\begin{array}{l}\text { Floor } \\
\text { Reaction } \\
\text { Location* } \\
\text { (cm) }\end{array}$} & \multicolumn{4}{|c|}{ Required joint torquest $(\mathrm{N} \mathrm{m})$} \\
\hline & & Ankle & Knee & Hip & Shoulder \\
\hline \multicolumn{6}{|c|}{ Force $(\mathrm{N})$ exerted at $50^{\circ}$ angle } \\
\hline 120 & 5.5 & 27 & 108 & 64 & 33 \\
\hline 130 & 6.2 & 31 & 106 & 62 & 35 \\
\hline 140 & 6.9 & 34 & 104 & 60 & 37 \\
\hline 150 & 7.7 & 37 & 102 & 59 & 39 \\
\hline 160 & 8.4 & 40 & 99 & 57 & 42 \\
\hline 170 & 9.2 & 44 & 97 & 56 & 44 \\
\hline 180 & 10.0 & 47 & 95 & 54 & 46 \\
\hline \multicolumn{6}{|c|}{ Angle $\left({ }^{\circ}\right)$ of exertion of $150 \mathrm{~N}$ force } \\
\hline 35 & 10.5 & 55 & 100 & 69 & 49 \\
\hline 40 & 9.7 & 49 & 100 & 65 & 46 \\
\hline 45 & 8.7 & 43 & 101 & 62 & 43 \\
\hline 50 & 7.7 & 37 & 102 & 59 & 39 \\
\hline 55 & 6.4 & 30 & 103 & 56 & 36 \\
\hline 60 & 5.1 & 23 & 104 & 53 & 32 \\
\hline 65 & 3.7 & 16 & 106 & 50 & 28 \\
\hline
\end{tabular}

* Anterior of ankle joints.

† Total for two joints. Positive entries correspond to ankle plantarflexion, knee extension, hip extension and shoulder flexion. The configuration analyzed was the Phase 1 end mean configuration of the old able group rising with the use of hands.

force on the armrests at liftoff of approximately $150 \mathrm{~N}$ at an angle of approximately $50^{\circ}$ with respect to the horizontal. Table 6 shows the effects of hypothetical variations in both this push magnitude and direction, as calculated in the Set 4 analyses.
The floor reaction location moves anteriorly if the hand push magnitude is increased and moves posteriorly if the push direction is made more vertical. The use of larger push magnitudes has mixed effects on torques, increasing the required ankle and shoulder torques and slightly decreasing the required knee and hip torques. In contrast, the use of a more vertical push direction increases the required knee torques only slightly while substantially decreasing the required ankle, hip and shoulder torques.

\section{DISCUSSION}

\section{Assumptions made in the analyses}

The model analyses assumed that inertial loads were negligible. This assumption seems reasonable in old subjects who tend to rise from a chair slowly, but inertial loads may not be negligible when subjects rise from a chair rapidly. The importance of dynamics in chair rises has not yet been studied comprehensively, and this needs to be done. Ikeda et al. (1991) recently reported some data on this topic.

The model analyses were two-dimensional. This seems reasonable in that the subjects studied by Alexander et al. (1991) did rise in an essentially sagittally symmetric manner.

\section{Significance of conditions as liftoff}

The results presented here consider mainly floor reaction location and joint torque requirements at the instant of liftoff from the seat. Floor reaction location is of interest because, once liftoff occurs and the hand support is not available, it is a measure of postural 
stability. The stability is maximum when the floor reaction is centered between the heels and the toes. Prior to liftoff, the support of the seat provides ample postural stability and the reaction location is not of particular interest. After liftoff, the body segments are moved into their upright standing configuration in which postural stability is relatively easier to achieve. Thus, postural stability seems most threatened just when liftoff from the seat occurs.

Similarly, prior to liftoff, the hand and seat support forces keep joint torque requirements small. Joint torque requirements also become quite small once upright standing configurations are achieved. It is not yet known whether joint torque requirements are maximum at liftoff, but Ikeda et al. (1991) report that $k$ nee and hip torques reach maximum values either at liftoff or shortly thereafter. For these reasons, this study examined primarily the conditions at liftoff.

\section{Required liftoff torques and voluntary strengths}

Comparisons of joint torque requirements with joint torque strengths show the extent to which the inability to rise from a chair might result from a decline in the muscular strength. In answer to question (5), the model-calculated ankle, knee, hip and shoulder torques required at liftoff from the seat when rising with or without hand use (Table 5), when compared to literature data on maximum voluntary joint torque strengths (Table 7), were well below the strengths reported, even for subjects over 80 years old and even given the variability usually found in reports of voluntary strength studies. Only Whipple et al. (1987).

Table 7. Literature values for joint torque strengths $(\mathrm{N} \mathrm{m})^{*}$

\begin{tabular}{|c|c|c|c|c|}
\hline \multirow[b]{2}{*}{ Data source } & \multicolumn{2}{|c|}{ Young adult $\dagger$} & \multicolumn{2}{|c|}{ Old $\ddagger$} \\
\hline & Females & Males & Females & Male: \\
\hline \multicolumn{5}{|l|}{ Ankle dorsiflexors } \\
\hline Oberg et al. (1987) & 98 & & & \\
\hline Sepic et al. (1986) & 88 & 156 & 92 & 148 \\
\hline Whipple et al. (1987) fallers $\S$ & & & & 2 \\
\hline Whipple et al. (1987) controls $\S$ & & & & 8 \\
\hline \multicolumn{5}{|l|}{ Ankle plantarflexors } \\
\hline Oberg et al. (1987) & 376 & & & \\
\hline Gerdle and Fugl-Meyer (1985) & & & 156 & 278 \\
\hline Falkel (1978) & 116 & 174 & & \\
\hline Sepic et al. (1986) & 200 & 258 & 164 & 262 \\
\hline Whipple et al. (1987) fallers $\S$ & & & & 11 \\
\hline Whipple et al. (1987) controls $\S$ & & & & 32 \\
\hline \multicolumn{5}{|l|}{ Knee flexors } \\
\hline Knapic et al. (1983) & 174 & 290 & & \\
\hline Borges (1989) & 200 & 310 & 130 & 218 \\
\hline Murray et al. (1985a) & 156 & & 100 & \\
\hline Whipple et al. (1987) fallers $\S$ & & & & 30 \\
\hline Whipple et al. (1987) controls $\$$ & & & & 62 \\
\hline \multicolumn{5}{|l|}{ Knee extensors } \\
\hline Knapic et al. (1983) & 320 & 500 & & \\
\hline Dannenskiold et al. (1984) & & 150 & 240 & \\
\hline Aniansson et al. (1980) & & & 216 & 382 \\
\hline Borges (1989) & 366 & 578 & 256 & 376 \\
\hline Murray et al. (1985a) & 352 & & 220 & \\
\hline Whipple et al. (1987) fallers $\S$ & & & & 52 \\
\hline Whipple et al. (1987) controls $\S$ & & & & 90 \\
\hline \multicolumn{5}{|l|}{ Hip flexors } \\
\hline Markhede and Grimby (1980) & & 240 & & \\
\hline Cahalan et al. (1989) & 132 & 216 & 102 & 178 \\
\hline \multicolumn{5}{|l|}{ Hip extensors } \\
\hline Markhede and Grimby (1980) & & 496 & & \\
\hline Cahalan et al. (1989) & 252 & 408 & 220 & 406 \\
\hline \multicolumn{5}{|l|}{ Shoulder flexors } \\
\hline Murray et al. (1985b) & 100 & 208 & 76 & 168 \\
\hline \multicolumn{5}{|l|}{ Shoulder extensors } \\
\hline Murray et al. (1985b) & 106 & 160 & 70 & 148 \\
\hline
\end{tabular}

* Most values quoted are for isometric strengths, but a few are for low-rate isokinetic strengths. Strengths have been doubled in order to compare them with the two-sides values calculated by the model.

$\dagger$ Mean age approximately $25-30 \mathrm{yr}$, see references.

$\$$ Mean age approximately $60-80$ yr, see references.

$\S$ These were nursing-home residents. Strengths were measured isokinetically. 
in a group of elderly nursing-home residents tested isokinetically at $60^{\circ} \mathrm{s}^{-1}$, found ankle plantarflexor strengths summed over left and right sides to be smaller than $39 \mathrm{~N} \mathrm{~m}$ or knee extensor strengths to be smaller than $119 \mathrm{Nm}$. It appears from these comparisons that, with the possible exception of people who are very frail or who have substantial joint pain, joint torque requirements may not be a major factor limiting the ability to lift off from a chair.

To some degree, these comparisons of the required and the reported strengths might be questioned because the reported strengths were not always measured in body configurations approximating those used at seat liftoff. On the other hand, some reports show that joint torque strengths do not differ substantially at different joint angles (Knapic et al., 1983; Murray et al., 1985; Cahalan et al., 1989, for example). Moreover, the evidence presented here from the Set 4 analyses that subjects do not opt for minimum joint torque requirements also suggests that, generally, the required joint torques are notably smaller than the available joint torques.

All earlier reports of chair rise biomechanics seem to consider torque requirements only at the ankles, knees and hips. The present analyses considered upperextremity torque requirements as well, although only shoulder torque requirements have been reported here. Shoulder torque requirements were usually not large, but the largest mean value computed $(37 \mathrm{~N} \mathrm{~m})$ begins to approach maximum voluntary strengths for old females $(70 \mathrm{Nm}$ ). These data suggest that at least some frail people may be limited in chair rise performances by inadequate upper-extremity strengths.

\section{Postural stability at liftoff}

The analyses presented here of the data reported by Alexander et al. (1991) suggest that subjects, at liftoff from the seat, may place a higher priority on achieving postural stability through placement of the floor reaction location than on reducing joint torque requirements. Moreover, old adults, including those with no apparent difficulty in rising, seem to place a higher priority on this stability than do young adults. The reasons underlying these conclusions follow.

Alexander et al. found that, when rising without the use of hands, old subjects rotated their upper body segments, thighs and legs significantly more than did young adult subjects. The biomechanical model analyses show (Table 5) that these age group segment rotation differences led to only modest differences in the joint torques needed at liftoff, but the larger segment rotations resulted in a more anterior floor reaction location. Presumably, they choose this more anterior location because of an increased concern over falling backwards.

When rising with the use of hands, a similar preference for reaction location placement over torque reduction seemed to exist (Table 5). The torque requirements for the old groups differed little from those for the young. Only the knee torques required by the old unable group were significantly smaller than those of the other two groups. In contrast, there were clear group differences in floor reaction locations at liftoff. The old unable group placed the floor reaction the most anterior, the old able group placed it intermediately and young group placed it the least anterior.

Perhaps the most convincing argument that, at liftoff, more premium is placed on stability than on strength requirements comes from the Set 4 analyses of the effects of changing the hand force direction. These analyses showed (Table 6) that exerting hand forces more in a vertical and less in a horizontal direction reduces three of the four major joint torques while leaving the fourth essentially unchanged. Despite this, all three subject groups whose data were analyzed chose not to push as vertically as they might have. The cost of pushing more vertically is to move the floor reaction location backwards. The three groups chose instead (Table 5) to have the floor reaction $4-11 \mathrm{~cm}$ anterior of the ankles, although other choices could have reduced the torque requirements. The heels lie approximately $8 \mathrm{~cm}$ posterior, and the toes approximately $20 \mathrm{~cm}$ anterior of the ankles. The floor reaction locations selected by these groups were well within these limits for postural stability at liftoff.

Use of the hands to assist a rise is clearly helpful, since some subjects cannot rise without their use. But, contrary to our expcctations, our results suggest that hands may not be used to reduce joint torque requirements, at least at liftoff. Rather, at liftoff, they may be used to gain increased postural stability.

Thus, in answer to question (6), our analyses suggest that, in their choices of body configuration and hand force use at liftoff from the seat support, all subject groups placed more importance on locating the floor reaction force to achieve acceptable postural stability than they did on reducing joint muscle strength requirements. The strategies chosen for rising provided the old unable group with the most stability, the old able with less, and the young group with the least.

If the achievement of postural stability at liftoff is indeed a major determinant of the ability to rise from a chair, there probably are ways to enhance this achievement. Better anteroposterior stability can be secured by getting the feet beneath the upper body segments, either by bringing the feet backwards under the body or by moving the body forwards over the feet. The data in Table 4 show how effective such a maneuver can be. A chair that enables the feet to be brought under it enables easier and safer rises.

\section{CONCLUSION}

These analyses suggest that the joint torque strength decreases that accompany aging and perhaps even frailty may seldom limit the ability to rise from a chair. People seem to place more importance on 
achieving acceptable postural stability at liftoff than they do on reducing the joint muscle strengths required to rise. In the groups we studied, the strategies chosen for rising provided the old unable with the most stability at liftoff, the old able with less, and the young with the least.

Acknowledgements-The support of Public Health Service Grants AG 06621 and AG 08808, the Dana Foundation and the Vennema Endowment, and the contributions of the Glacier Hills Retirement Center and the Turner Geriatric Clinic in this research are gratefully acknowledged.

\section{REFERENCES}

Alexander, N. B., Schultz, A. B. and Warwick, D. N. (1991) Rising from a chair: effects of age and functional ability on performance biomechanics. J. Gerontol. Med. Sci. 46, M91-98.

Aniansson, A., Grimby, G. and Rundgren, A. (1980) Isometric and isokinetic quadriceps muscle strength in 70 year-old men and women. Scand. J. Rehab. Med. 12 , $161-168$.

Anthropometric Source Book Volume 1: Anthropometry for Designers (1978). NASA Reference Book Publication 1024.

Bajd, T. and Kralj, A. (1982) Standing-up of a healthy subject and a paraplegic patient. J. Biomechanics 15, 1-10.

Borges, O. (1989) Isometric and isokinetic knee extension and flexion torque in men and women aged 20-70. Scand. J. Rehab. Med. 21, 45-53.

Burdett, R. G., Habsdevich, R., Pisciotta, J., et al. (1985) Biomechanical comparison of rising from two types of chairs. Phys. Ther. 65, 1177-1183.

Cahalan, T. D., Johnson, M. S., Liu, S., et al. (1989) Quantitative measurements of hip strength in different age groups. Clin. Orthop. 246, 136-145.

Danneskiold-Samsoe, B., Kofod, V., Munter, J., et al. (1984) Muscle strength and functional capacity in 78-81-year-old men and women. Eur. J. Appl. Physiol. 52, 310-314.

Dawson, D., Hendershot, G. and Fulton, J. (1987) Aging in the eighties. Functional limitations of individuals age 65 and over. Advance Data From Vital and Health Statistics 133, DHHS-PHS-87-1250, Public Health Service, Hyattsville MD

Ellis, M. I., Seedhom, B. B., Amis, A. A., et al. (1979) Forces in the knee joint whilst rising from normal and motorized chairs. Engng Med. 8, 33-40.

Ellis, M. I., Seedhom, B. B. and Wright, V. (1985) A comparison of knee joint and muscle forces in women 36 weeks pregnant and four weeks after delivery. Engng Med. 14, 95-99.

Falkel, J. (1978) Plantar flexor strength testing using the cybex isokinetic dynamometer. Phys. Ther. 58, 847-850.

Fleckenstein, S. J., Kirby, R. L and MacLeod, D. A. (1988) Effect of limited knee-flexion range on peak hip moments of force while transferring from sitting to standing. J. Biomechanics 21, 915-918.

Gerdle, B. and Fugl-Meyer, A. R. (1985) Mechanical output and IEMG of isokinetic plantar flexion in 40-64-year-old subjects. Acta. Physiol. Scand. 124, 201-211.

Ikeda. E. R., Schenkman, M. L., Riley, P. O. and Hodge W. A. (1991) Influence of age on dynamics of rising from a chair. Phys. Ther. 71, 473-481.

Jeng, S. F., Schenkman, M., Riley, P. O. and Lin, S. J. (1990) Reliability of a clinical kinematic assessment of the sit-tostand movement. Phys. Ther. 70, 511-520.

Jones, F. P., Hanson, J. A., Miller, J. F., et al. (1962)
Quantitative analysis of abnormal movement: the sit-10stand pattern. Am. J. Phys. Med. 42, 208-218

Kelley, D. L., Dainis, A. and Wood, G. K. (1976) Mechanics and muscular dynamics of rising from a seated position. In Biomechanics $V$-B. (Edited by Komi, P. V.), pp. 127-135. University Park Press, Baltimore.

Knapik, J. J., Wright, J. E., Mawdsley, R. H., et al. (1983) Isometric, isotonic, and isokinetic torque variations in four muscle groups through a range of joint motion. Phys. Ther. 63, 938-947.

Kralj, A., Jaeger, R. J. and Munih, M. (1990) Analysis of standing up and sitting down in humans. J. Biomechanics 23, $1123-1138$

Markhede, G and Grimby, G. (1988) Measurement of strength of hip joint muscles. Scand. J. Rehah. Med. 12 169-174.

Munton, J. S.. Ellis. M. I. and Wright. V. (1984) Use of electromyography to study leg muscle activity in patients with arthritis and in normal subjects during rising from a chair. Ann. Rheum. Dis, 43, 63-65.

Murray, M. P., Duthie, E. H., Gambert, S. R., et al. (1985a) Age-related differences in knee muscle strength in normal women. J. Gerontol. 40, 275-280.

Murray M. P., Gore, D. R., Gardner, G. M., et al (1985b) Shoulder motion and muscle strength of normal men and women in two age groups. Clin. Orthop. 192, 268-273.

Nemeth, G., Ekholm, J., Arborelius, U. P., et al, (1984) Hip joint load and muscular activation during rising exercises. Scand. J. Rehab. Med. 16, 93-102

Nuzik, S., Lamb, R., VanSant, A. and Hirt. S. (1986) Sit-tostand movement pattern. Phys. Ther. 66, 1708-1713.

Oberg, B. Bergman, T. and Tropp, H. (1987) Testing of isokinetic muscle strength in the ankle. Med. Sci. Sports Exercise. 19, 318-322.

Pai, Y. C. and Rogers, M. W. (1990) Control of body mass transfer as a function of speed of ascent in sit-to-stand Med. Sci. Sports Exercise 22, 378-384.

Pai, Y. C. and Rogers, M. W. (1991) Segmental contributions of total body momentum in sit-to-stand. Med. Sci. Sport: Exercise 23, 225-230

Riley, P. O., Schenkman, M. L., Mann, R. W. and Hodge, W. A. (1991) Mechanics of a constrained chair rise. $J$ Biomechanics 24, 77-85.

Rodosky, M. W., Andriacchi, T. P. and Andersson, G. B. J. (1989) The influence of chair height on lower limb mechanics during rising. J. orthop. Res. 7, 266-271.

Schenkman, M., Berger, R. A., Riley, P. O., et al. (1990) Whole-body movements during rising to standing from sitting. Phys. Ther. 70, 638-649.

Seedhom, B. B. and Terayama, K. (1976) Knee forces during the activity of getting out of a chair with and without the aid of arms. Biomed. Engng 11, 278-282.

Sepic, S. B., Murray, M. P., Mollinger, L. A.. et al. (1986) Strength and range of motion in the ankle in two age groups of men and women. Am. J. Phys. Med. 65, 75-84.

Stevens, C., Bojsen-Moller, F. and Soames, R. W. (1989) The influence of initial posture on the sit-to-stand movement Eur. J. appl. Physiol. 58, 687-692.

Wheeler, J., Woodward, C., Ucovich, R. L., et ul. (1985) Rising from a chair. Phys. Ther. 65, 22-26.

Whipple, R. H., Wolfson, L. I. and Amerman, P. M. (1987) The relationship of knee and ankle weakness to falls in nursing home residents: an isokinetic study. J. Am. Geriatrics Soc. 35, 13-20.

Yoshida, K., Iwakura, H. and Inoue, F. (1985) Motion analysis in the movements of standing up from and sitting down on a chair: a comparison of normal and hemiparetic subjects and the differences of sex and age among the normals. Scand. J. Rehab. Med. 15, 133-140 